\title{
RASSF1A suppresses oncogenic H-Ras-induced c-Jun N-terminal kinase activation
}

\author{
YOUNG A. YOO ${ }^{1,2}$, AH RAM NA ${ }^{1,2}$, MYEONG-SOK LEE ${ }^{4}$, \\ SUKJOON YOON ${ }^{4}$, JUN SUK KIM ${ }^{2,3}$ and YOUNG DO YOO ${ }^{1,2}$ \\ ${ }^{1}$ Graduate School of Medicine, ${ }^{2}$ Brain Korea 21 Project for Biomedical Science, ${ }^{3}$ Department of \\ Internal Medicine, Korea University College of Medicine, Korea University, Seoul 136-705; \\ ${ }^{4}$ Department of Biological Sciences, Sookmyung Women's University, Seoul 140-742, Korea
}

Received July 3, 2006; Accepted September 1, 2006

\begin{abstract}
The constitutive activation of JNK has been implicated in Ras-induced cellular transformation and activated JNK is down-regulated by the tumor suppressor protein, RASSF1A. In this study, we examined whether RASSF1A blocked oncogenic Ras-induced JNK activation. Exogenous expression of H-Ras ${ }^{\mathrm{G} 12 \mathrm{~V}}$ induced JNK phosphorylation and RASSF1A co-transfected with H-Ras ${ }^{G 12 V}$ efficiently suppressed Ras-triggered JNK activation in various cancer cell lines. RASSF1A expression revived the H-Ras ${ }^{\mathrm{G} 12 \mathrm{~V}}$ induced $\mathrm{p} 27^{\mathrm{Kip} 1}$ down-regulation. JNK siRNA treatment also promoted recovery from the $\mathrm{H}-\mathrm{Ras}^{\mathrm{G} 12 \mathrm{~V}}$-induced $\mathrm{p} 27^{\mathrm{Kip} 1}$ downregulation. These results demonstrate that RASSF1A inhibited H-Ras ${ }^{G 12 V}$-induced JNK activation and JNK-mediated p $27^{\text {Kip } 1}$ down-regulation. From these results, we propose that RASSF1A exerts a tumor-suppressing effect by blocking oncogenic Ras-induced JNK activation.
\end{abstract}

\section{Introduction}

Many tumor suppressors are usually inactivated by loss of heterozygosity ( $\mathrm{LOH}$ ) mutation, or epigenetic inactivation during tumorigenesis. RASSF1A is also inactivated by LOH or by hypermethylation of its promoter region, resulting in its loss of expression in a variety of human cancers (1-3). The exact role of RASSF1A as a tumor suppressor is not fully understood, despite considerable study. Many tumor suppressors, such as $\mathrm{Rb}$ and $\mathrm{p} 53$, control the cell cycle, and their inactivation results in the failure of cell-cycle regulation, consequently contributing

Correspondence to: Dr Young Do Yoo, Graduate School of Medicine, Korea University College of Medicine, Korea University, 126-1, 5ka, Anam-dong, Sungbuk-ku, Seoul 136-705, Korea

E-mail: ydy1130@korea.ac.kr

Dr Jun Suk Kim, Department of Internal Medicine, Korea University College of Medicine, 126-1, 5ka, Anam-dong, Sungbuk-ku, Seoul 136-705, Korea

E-mail: kjs6651@kumc.or

Key words: RASSF1A, JNK, H-Ras ${ }^{\mathrm{G} 12 \mathrm{~V}}, \mathrm{p} 21^{\mathrm{WAF} 1 / \mathrm{CIP} 1}, \mathrm{p} 27^{\mathrm{Kip} 1}$ to tumorigenesis. RASSF1A regulates the cell cycle like other tumor suppressors by arresting G1/S transition or mitotic progression. RASSF1A controls mitotic arrest by regulating the anaphase-promoting complex (APC)-Cdc 20 complex $(4,5)$. Ectopic RASSF1A expression inhibits cell-cycle progression in the G1 phase by cyclin D1 down-regulation in H1299 and A549 cells $(6,7)$. RASSF1A also controls another cyclin, cyclin A2. Increased RASSF1A expression induces cyclin A2 expression transcriptionally through an increase of the binding activity of $\mathrm{p} 120^{\mathrm{E} 4 \mathrm{~F}}$ to the cyclin A2 promoter (8).

Ras is a key protein that regulates various cellular signaling pathways, including cell proliferation and malignant transformation (9). Activated Ras resulting from point mutation plays an important role in cancer development, and also is involved in the induction of many downstream mediators. One of these is the c-Jun NH2-terminal kinase (JNK). Ras regulates the JNK signal transduction pathway $(10,11)$. Oncogenic Ras-mediated JNK activation contributes to cellular transformation (12). The constitutive activation of JNK has also been observed in cancer cell lines and tumor tissues, and contributes to tumor cell growth (13-18). JNK activation by a constitutively active SAPKB-MKK7 causes NIH3T3 cells to express a partially transformed phenotype (19). One of the downstream targets of JNK is known to be a transcription factor, c-Jun, and c-Jun phosphorylation is involved in Rasinduced transformation (20).

In a previous study, we reported that RASSF1A reduced JNK activation and c-Jun phosphorylation, and suggested that RASSF1A exerts a tumor-suppressing effect by blocking oncogene-mediated JNK activation (21). As mentioned above, oncogenic Ras-mediated JNK activation contributes to cellular transformation (12). Therefore, we assumed that RASSF1A might exert a tumor-suppressing role in Ras-induced cellular transformation, especially JNK-mediated transformation. In the present study, we investigated the involvement of RASSF1A in the control of JNK activation that is related to oncogenic H-Ras.

\section{Materials and methods}

Cell lines and reagents. Cell lines used in these experiments were purchased from the American Type Culture Collection 
(ATCC, Manassas, VA). A549 and BEAS-2B cells were cultured at $37^{\circ} \mathrm{C}$ in a humidified chamber of $5 \% \mathrm{CO}_{2}$. The culture medium was Ham's F-12 (Gibco/BRL, Grand Island, NY) containing $10 \%$ heat-inactivated fetal bovine serum (FBS) $(\mathrm{Gibco} / \mathrm{BRL})$, sodium bicarbonate $(2 \mathrm{mg} / \mathrm{ml})$, penicillin (100 U/ml), and streptomycin (100 $\mu \mathrm{g} / \mathrm{ml})$. MCF-7 and 293T cells were cultured in IMDM and DMEM supplemented with 10\% FBS, respectively. The NCI-H1299 (H1299) cells were cultured in RPMI-1640 (Gibco/BRL, Grand Island, NY) containing $10 \%$ heat-inactivated fetal bovine serum (Gibco/BRL), sodium bicarbonate $(2 \mathrm{mg} / \mathrm{ml})$, penicillin $(100 \mathrm{U} / \mathrm{ml})$, streptomycin $(100 \mu \mathrm{g} / \mathrm{ml})$ at $37^{\circ} \mathrm{C}$ in a humidified chamber of $5 \% \mathrm{CO}_{2}$. The kinase inhibitors, SP600125 and PD98059, were purchased from Calbiochem (San Diego, CA) and LY294002 was purchased from Sigma-Aldrich (St. Louis, MO).

Transfection. Cells $\left(1 \times 10^{5}\right)$ were seeded on 60 -mm culture dishes and grown for $24 \mathrm{~h}$ before transfection. Cells were transfected with either $H$-Ras ${ }^{G 12 V}(0.5 \mu \mathrm{g})$ alone, or with RASSF 1A $(1 \mu \mathrm{g})$, using lipofectamine 2000 reagent (Invitrogen, Carlsbad, CA).

Western blotting and cycloheximide treatment. Cells were transfected with plasmids, and lysed with RIPA buffer [50 mM Tris, $150 \mathrm{mM} \mathrm{NaCl}, 1 \%$ Triton $\mathrm{X}-100,0.1 \%$ SDS, $1 \% \mathrm{Na}-$ Deoxycholate ( $\mathrm{pH}$ 7.4)] supplemented with protease inhibitors (1 mM phenylmethylsulfonyl fluoride, $10 \mu \mathrm{g} / \mathrm{ml}$ peptasin A, $10 \mu \mathrm{g} / \mathrm{ml}$ aprotinin and $5 \mu \mathrm{g} / \mathrm{ml}$ leupeptin). Protein concentrations were measured using the Bio-Rad protein assay kit (Bio-Rad, Hercules, CA). Protein lysates were separated by SDS-PAGE, and then transferred onto nitrocellulose membranes (Hybond ${ }^{\mathrm{TM}}-\mathrm{P}$, Amersham Biosciences, Piscataway, NJ) They were then blocked with phosphate-buffered saline (PBS) containing $0.2 \%$ Tween-20 and 5\% non-fat dry milk, incubated with primary antibody, and then with horseradish peroxidase-labeled secondary antibody. The signal was exposed on X-ray film. The antibodies used were polyclonal anti-phospho-SAPK/JNK (Thr183/Tyr185) antibody (Cell Signaling Technology, Beverly, MA), polyclonal anti-JNK antibody (Cell Signaling Technology), monoclonal antiRASSF1A antibody (eBiosciences, Minneapolis, MN), monoclonal anti-c-Ras antibody (Ab-1, Calbiochem), monoclonal anti-p27 ${ }^{\mathrm{Kip} 1}$ antibody (BD Transduction Laboratories, San Diego, CA), polyclonal anti-p21 $1_{\text {WAF1/CIP1 }}$ (C-19, Santa Cruz Biotechnology, Santa Cruz, CA), and monoclonal anti-ß-actin antibody (AC-74, Sigma). For cycloheximide treatment in $293 \mathrm{~T}$ and MCF-7 cells, the medium was supplemented with $50 \mu \mathrm{g} / \mathrm{ml}$ of cycloheximide (CHX, Sigma) $24 \mathrm{~h}$ after transfection with either H-Ras alone or with RASSF1A. The cells were then collected at the indicated time-points.

siRNA transfection. The double-stranded siRNA oligonucleotide used for targeting RASSF1A or fluorescence-labeled double-stranded RNA (dsRNA) oligomer (BLOCK iT ${ }^{\mathrm{TM}}$ fluorescence oligo) as a control were synthesized at Invitrogen. The RASSF1A siRNA sequences used were those published previously (5): sense, 5'-TGTGGAGTGGGAGACACCTTT-3'; and antisense, 5'-AGGTGTCTCCCACTCCACATT-3'. Cells were transfected with $100 \mathrm{nM}$ RASSFIA siRNA or control
dsRNA using lipofectamine 2000 reagent (Invitrogen), according to the manufacturer's instructions. In some of the experiments, the cells were treated with $100 \mathrm{nM} J N K$ siRNA as a specific inhibitor of JNK synthesis. The double-stranded siRNA oligonucleotides used for targeting $J N K$ (sense, 5'-AAA AAGAATGTCCTACCTTCTTT-3'; antisense, 5'-AGAAGG TAGGACATTCTTTTTTT-3') were synthesized at Invitrogen.

Reverse transcription-PCR. Total RNA was isolated using TRIzol reagent, according to the manufacturer's instructions (Life Technologies, Rockville, MD). Reverse transcription (RT) reactions were performed using $2 \mu \mathrm{g}$ of total cellular RNA with Molony murine leukemia virus reverse transcriptase (Life Technology) and oligo (dT) primers (Roche, Indianapolis, IN). The RT reaction mixtures were used as a template for the PCR amplification of RASSF $1 A$ and $\beta$-actin. Primers and conditions used for RASSF $1 A$ and $\beta$-actin RT-PCR were as previously described (21).

In vitro kinase assay. Non-radioactive JNK kinase assays were performed according to the manufacturer's protocol (Cell Signaling). Briefly, $20 \mu \mathrm{l}$ of re-suspended immobilized beads were incubated with $200 \mu \mathrm{g}$ of total protein lysate by gentle rocking overnight at $4{ }^{\circ} \mathrm{C}$. Then, the cell lysate/ immobilized c-Jun fusion protein was microcentrifuged at $12,000 \mathrm{rpm}$ for $30 \mathrm{sec}$ at $4^{\circ} \mathrm{C}$ and pellets were washed twice with $1 \mathrm{X}$ lysis buffer and twice with $1 \mathrm{X}$ kinase buffer. Pellets were suspended in $50 \mu 1$ of $1 \mathrm{X}$ kinase buffer supplemented with $100 \mu \mathrm{M}$ ATP and incubated for $30 \mathrm{~min}$ at $30^{\circ} \mathrm{C}$. The reactions were stopped with $25 \mu 1$ of $3 \mathrm{X}$ SDS sample buffer and the samples were then boiled for $5 \mathrm{~min}$. The $20 \mu \mathrm{l}$ samples were loaded onto a $12 \%$ SDS-polyacrylamide gel for electrophoresis and transferred to a nitrocellulose membrane. The blots were incubated with phospho-c-Jun (Ser63) antibody.

\section{Results}

To determine that RASSF1A suppresses the H-Ras ${ }^{\mathrm{G} 12 \mathrm{~V}}$ induced JNK activation, oncogenic H-Ras and/or RASSF1A were introduced into $\mathrm{H} 1299$ cells, cells in which the RASSF 1A promoter is epigenetically inactivated and therefore RASSF1A is not expressed. Fig. 1A shows that increased H-Ras ${ }^{\mathrm{G} 12 \mathrm{~V}}$ expression induced JNK phosphorylation. This result is consistent with a previous report (12). Next, we co-transfected the cells with $H-R_{a s}{ }^{G I 2 V}$ and RASSF 1A. Exogenous expression of RASSF1A suppressed H-Ras-induced JNK phosphorylation (Fig. 1A). This result was confirmed in another cell line, A549, in which RASSF1A is also epigenetically inactivated. Fig. 1B shows that RASSF1A expression inhibited H-Ras ${ }^{\mathrm{G} 12 \mathrm{~V}}$ induced JNK activation in A549 cells. We examined this effect in three additional cell lines, 293T, MCF-7 and BEAS-2B. In keeping with the results seen in Fig. 1A and B, RASSF1A introduction blocked H-Ras ${ }^{\mathrm{G} 12 \mathrm{~V}}$-induced JNK activation, even though RASSF1A is expressed in 293T and BEAS-2B cells (Fig. 1C and E). To further examine the inhibition of JNK phosphorylation by RASSF1A, we performed an in vitro kinase assay using the immobilized c-Jun bead as the substrate for JNK. Consistent with the results shown in Fig. 1C, HRas $^{\mathrm{G} 12 \mathrm{~V}}$ expression enhanced c-Jun phosphorylation (Fig. 1F). As a positive control, SP600125, a specific JNK inhibitor (21), 
A H1299

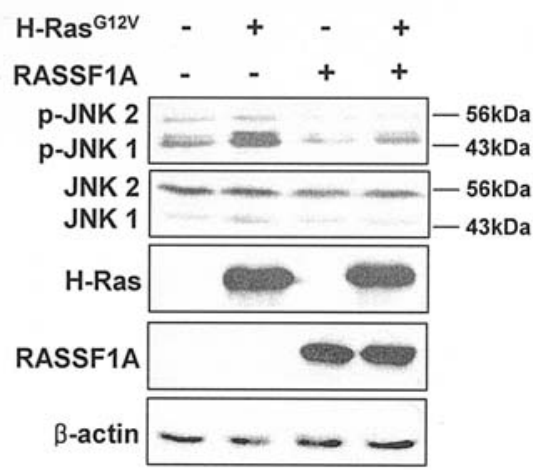

C 293T

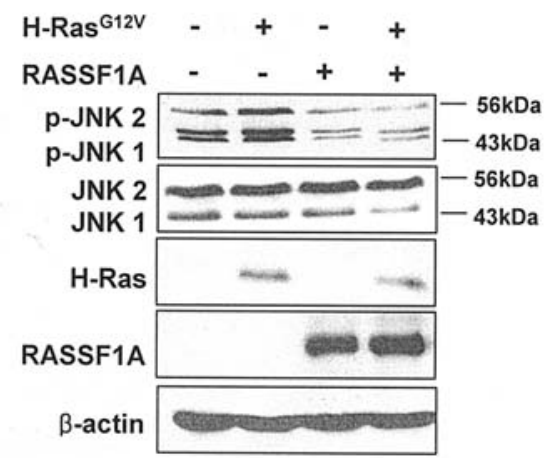

B A549

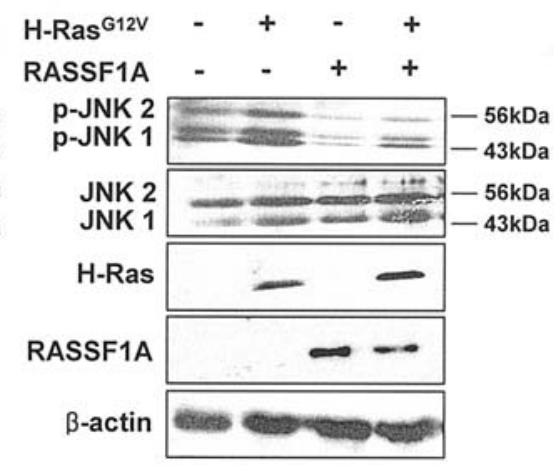

D MCF-7

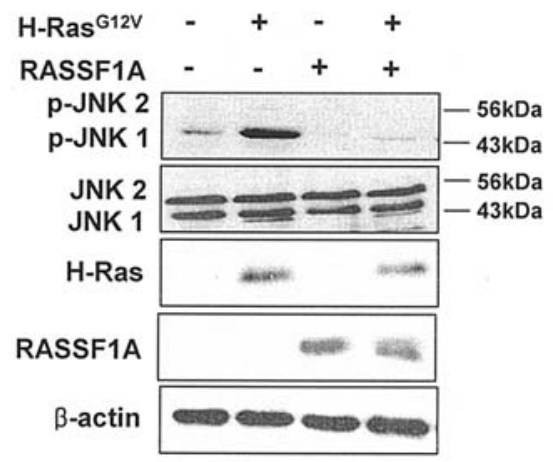

E BEAS-2B

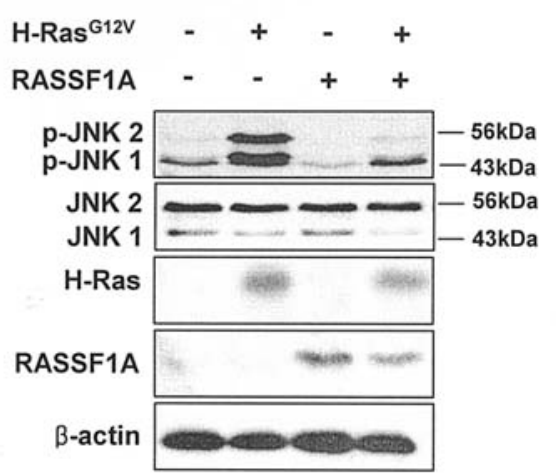

F

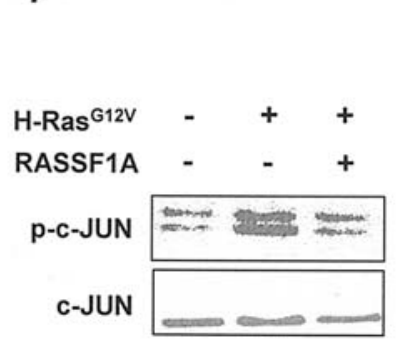

G

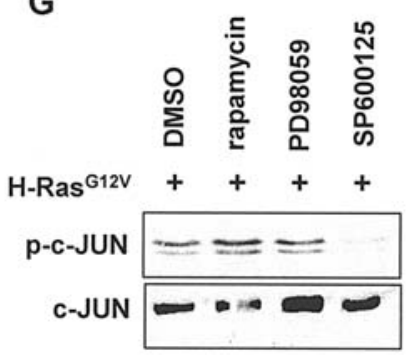

Figure 1. Effect of RASSF1A on H-Ras ${ }^{\mathrm{G} 12 \mathrm{~V}}$-induced JNK activation. Cell lysates (40 $\left.\mu \mathrm{g}\right)$ of H1299 (A), A549 (B), $293 \mathrm{~T}$ (C), MCF-7 (D) and BEAS-2B (E) cells transiently transfected with either $H-\operatorname{Ras}^{G I 2 V}(0.5 \mu \mathrm{g})$ alone, or with $R A S S F 1 A(1 \mu \mathrm{g})$, were subjected to Western blotting with anti-phospho JNK, anti-JNK, anti-Ras, anti-RASSF1A, or anti-B-actin. (F) Lysates of 293T cells transfected with either H-Ras ${ }^{G I 2 V}$ alone, or with RASSF1A, were subjected to immune complex kinase assays with the immobilized c-Jun bead as a JNK substrate. (G) $293 \mathrm{~T}$ cells transfected with $H$-Ras ${ }^{G 12 V}$ alone were treated with rapamycin (20 $\left.\mu \mathrm{M}\right)$, PD98059 $(20 \mu \mathrm{M})$, or SP600125 $(30 \mu \mathrm{M})$. Cell lysates were subjected to in vitro JNK kinase assay.

was used to treat 293 T cells. SP600125 treatment blocked c-Jun phosphorylation (Fig. 1G). However, the MEK inhibitor
PD98059 did not inhibit JNK activity, and neither did the mTOR inhibitor rapamycin, which inhibits the phosphorylation 
A

293T
BEAS-2B

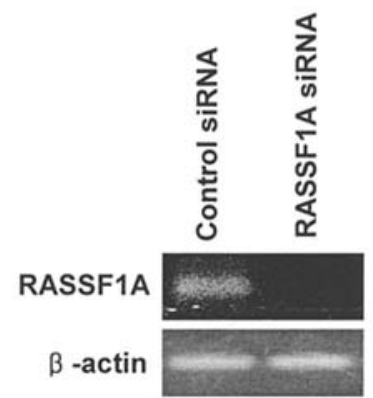

B $293 T$

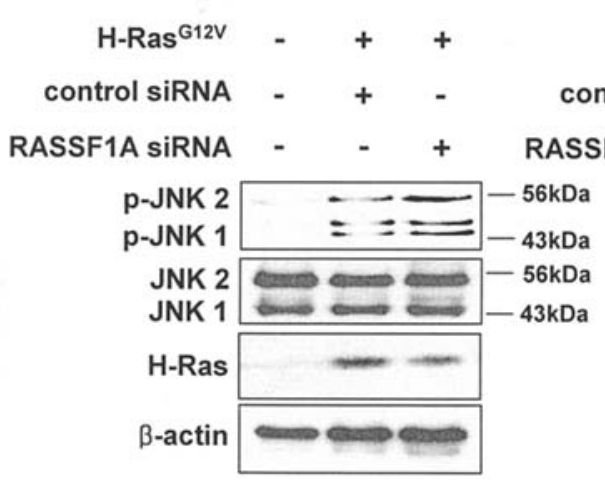

D 293T

\section{BEAS-2B}

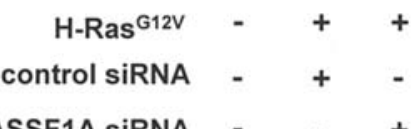

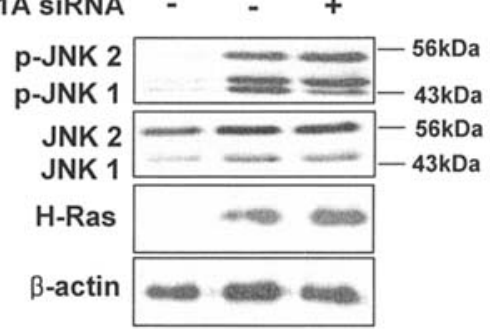

E BEAS-2B

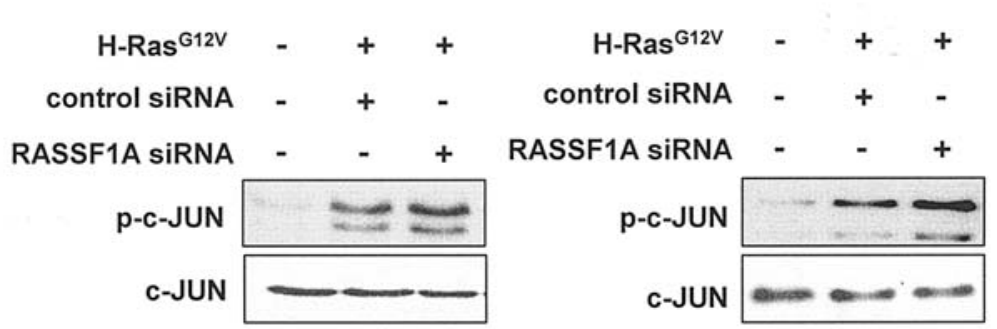

Figure 2. Enhancement of JNK activation by treatment with RASSF1A siRNA. (A) 293T cells were transfected with RASSF1A siRNA or control dsRNA and harvested $24 \mathrm{~h}$ later. RT-PCR for endogenous RASSF1A transcripts was performed. B-actin transcripts served as a loading control. 293T (B) and BEAS-2B (C) cells were co-transfected with $H$-Ras ${ }^{G I 2 V}$ and either RASSF1A siRNA or control dsRNA. Cell lysates were also subjected to Western blotting for the indicated proteins. For in vitro kinase assays, lysates of $293 \mathrm{~T}$ (D) and BEAS-2B (E) cells were subjected to in vitro JNK kinase assays.

and activation of p70S6K. In agreement with the Western blotting, as shown in Fig. 1C, an in vitro kinase assay showed that the introduction of RASSF1A markedly reduced JNK activity in the cells that had shown an increase in JNK activity due to H-Ras ${ }^{\mathrm{G} 12 \mathrm{~V}}$ expression, as was observed for the cells treated with SP600125 (Fig. 1G). These results suggest that RASSF1A suppressed the oncogenic H-Ras-induced JNK activation.

In our previous report, we showed that transient transfection of RASSF IA siRNA into BEAS-2B or RASSF1A-overexpresing H1299 cells enhanced JNK activity (21). We also used siRNA to inhibit RASSF1A expression, as previously reported (5). Transient transfection of RASSF1A siRNA into 293T or BEAS-2B cells efficiently down-regulated RASSF1A expression (Fig. 2A). We then examined whether siRNA-mediated blocking of RASSF1A expression could enhance the JNK activity that was up-regulated by $\mathrm{H}-\mathrm{Ras}^{\mathrm{G} 12 \mathrm{~V}}$ expression. Fig. 2B and $\mathrm{C}$ show that the siRNA-mediated blocking of endogenous RASSF1A expression slightly enhanced JNK phosphorylation. JNK activity was also examined by an in vitro kinase assay in these cell lines. As shown in Fig. 2D and E, the siRNA-mediated blocking of RASSF1A expression slightly enhanced the JNK activity in both cell lines. This result is consistent with Fig. 2B and C. Taken together, these results clearly indicate that RASSF1A suppressed H-Ras induced JNK activation.

The Ras/Raf pathway has an important role in mediating growth factor signaling. Through this pathway, many target proteins are induced or repressed. Ras up-regulates the expression of c-Jun and p21 $1^{\mathrm{WAF} 1 / \mathrm{CIP} 1}$. Meanwhile, downregulation of $\mathrm{p} 27^{\mathrm{Kip} 1}$ is required for entry to the S-phase $(22,23)$. Therefore, we examined whether RASSF1A regulated the expression of H-Ras downstream target proteins. 293T cells were transiently transfected with $H-\operatorname{Ras}^{G 12 V}$ and/or RASSF IA, 
A $293 T$

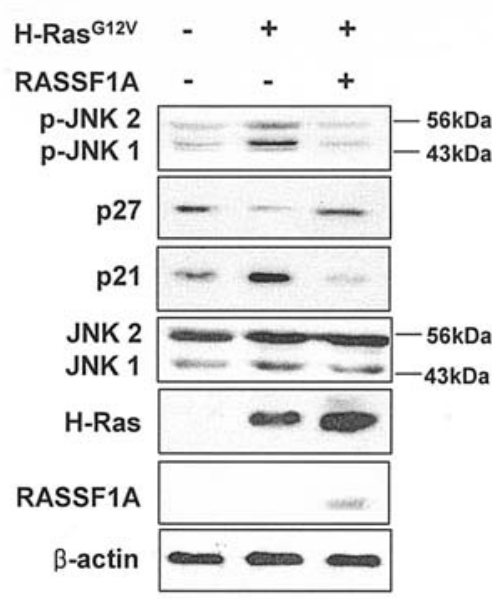

C 293T

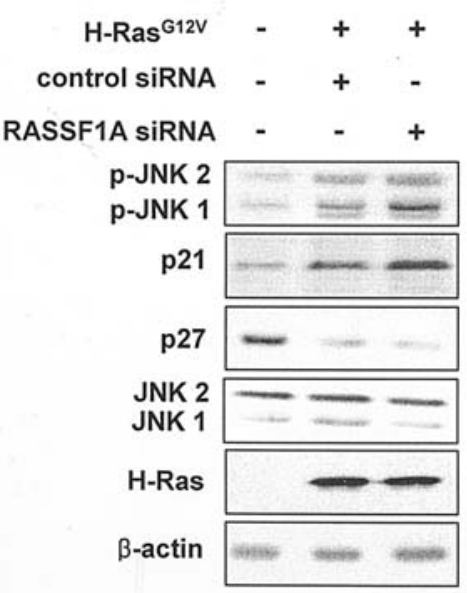

B MCF-7

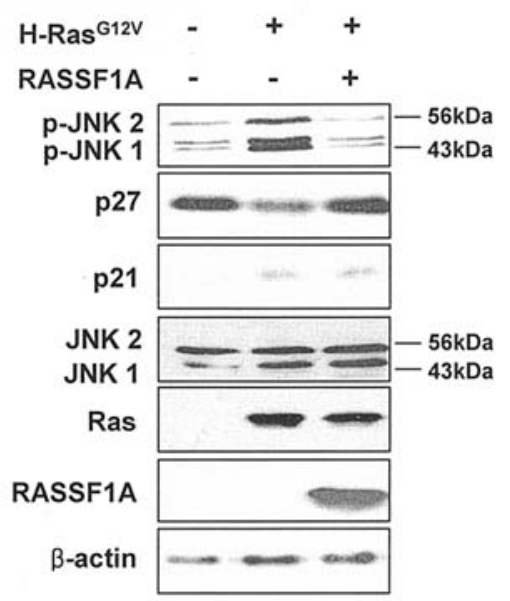

D 293T

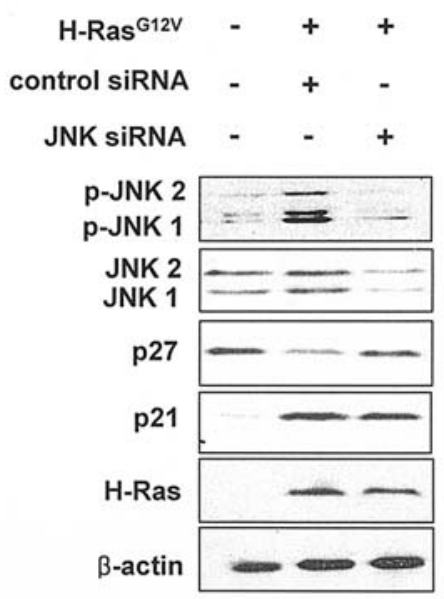

Figure 3. RASSF1A revived H-Ras ${ }^{\mathrm{G} 12 \mathrm{~V}}$-induced $\mathrm{p} 27^{\mathrm{Kip} 1}$ down-regulation in $293 \mathrm{~T}$ (A) and MCF-7 (B) cells. Cell lysates (40 $\left.\mu \mathrm{g}\right)$ of $293 \mathrm{~T}$ and MCF-7 cells transiently co-transfected with either $H$-Ras ${ }^{G 12 V}$ alone, or with RASSF1A, were separated by SDS-PAGE, and Western blotting was performed with the indicated antibodies. (C) $293 \mathrm{~T}$ cells were co-transfected with $H$-Ras ${ }^{G I 2 V}$ and with either RASSF1A siRNA or control dsRNA. Extracts were subjected to SDS-PAGE and Western blotting was performed with the indicated antibodies. (D) JNK-mediated p27 ${ }^{\mathrm{Kip} 1}$ down-regulation by H-Ras ${ }^{\mathrm{G} 12 \mathrm{~V}}$. 293T cells were co-transfected with $H$-Ras ${ }^{G 12 V}$ and either JNK siRNA or control dsRNA. After 24 h, $40 \mu$ g cell lysates were separated by SDS-PAGE, and Western blotting was performed with the indicated antibodies.

and Western blotting was performed. Consistent with Fig. 1, $\mathrm{H}$-Ras induced JNK activity and this was blocked by exogenous expression of RASSF1A (Fig. 3). Fig. 3A shows that H-Ras ${ }^{\mathrm{G} 12 \mathrm{~V}}$ expression down-regulated $\mathrm{p} 27^{\mathrm{Kip} 1}$ expression, and that RASSF1A co-transfected with $H$-Ras ${ }^{G I 2 V}$ recovered p27 Kip1 expression that had been down-regulated by H-Ras ${ }^{\mathrm{G} 12 \mathrm{~V}}$ expression. Similarly, p $21^{\text {WAF1/CIP1 }}$ was induced by H-Ras ${ }^{\mathrm{G} 12 \mathrm{~V}}$ expression and RASSF1A co-transfected with $\mathrm{H}$-Ras ${ }^{G 12 \mathrm{~V}}$ inhibited $\mathrm{p} 21^{\mathrm{WAF} 1 / \mathrm{CIP} 1}$ induction. Inhibition of $\mathrm{H}-\mathrm{Ras}^{\mathrm{G} 12 \mathrm{~V}}$ mediated $\mathrm{p} 27^{\mathrm{Kip} 1}$ down-regulation by RASSF1A was also observed in MCF-7 cells (Fig. 3B). However, p21 $1^{\mathrm{WAF} 1 / \mathrm{CIP} 1}$ induction by $\mathrm{H}-\mathrm{Ras}^{\mathrm{G} 12 \mathrm{~V}}$ was not influenced by RASSF1A expression in these cells. This difference is probably due to a cell-type specific phenomenon. We used siRNA to inhibit endogenous RASSF1A expression, as has been previously reported (5). Transient transfection of RASSF1A siRNA into 293T cells slightly enhanced JNK phosphorylation (Fig. 3C). Enhancement of p21 WAF1/CIP1 induction and p27 Kip1 downregulation were also observed in cells that were transfected with RASSF1A siRNA. In the present study, H-Ras ${ }^{\mathrm{G} 12 \mathrm{~V}}$ upregulated $\mathrm{p} 21^{\mathrm{WAF} 1 / \mathrm{CIP} 1}$ expression. This effector, $\mathrm{p} 21^{\mathrm{WAF} 1 / \mathrm{CIP} 1}$, is a cell-cycle inhibitor that blocks the cell cycle transition from the G1 phase to S-phase. However, it is often induced by growth factor signaling, probably promoting the association of cyclin D and Cdk (24). Recent reports have demonstrated that JNK is required for PDGF-induced $p 21^{\text {WAFI/CIPI }}$ promoter activity independent of p53, and that RASSF1A suppresses JNK activity $(21,25)$. Therefore, we examined whether JNK mediated the $\mathrm{H}-\mathrm{Ras}^{\mathrm{G} 12 \mathrm{~V}}$-induced $\mathrm{p} 21^{\mathrm{WAF} 1 / \mathrm{CIP} 1}$ induction and p27 ${ }^{\text {Kipl }}$ down-regulation. We used siRNA to inhibit endogenous JNK expression. Transient transfection of JNK siRNA into $293 \mathrm{~T}$ cells efficiently down-regulated JNK expression (Fig. 3D). Blocking of H-Ras ${ }^{\mathrm{G} 12 \mathrm{~V}}$-induced JNK activation by siRNA led to recovery of p27 ${ }^{\mathrm{Kip} 1}$ expression. However, there was no alteration observed in the amount of $\mathrm{p} 21^{\mathrm{WAF} 1 / \mathrm{CIP} 1}$ in these cells. The amount of $\mathrm{p} 27^{\mathrm{Kip} 1}$ protein in cells is regulated by transcriptional and post-transcriptional mechanisms $(26,27)$. Since the ectopic expression of RASSF1A inhibited H-Ras ${ }^{\mathrm{G} 12 \mathrm{~V}}$ - 


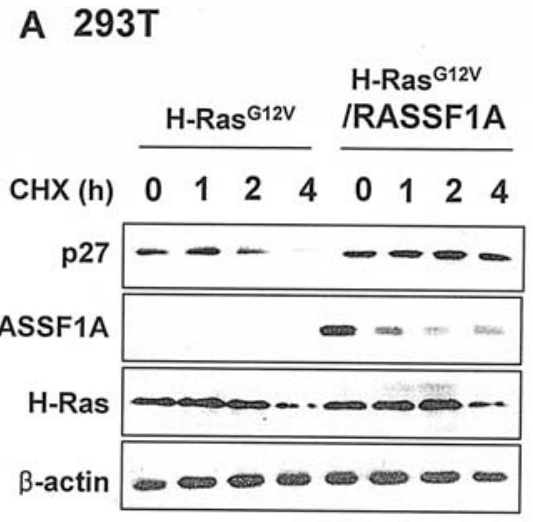

\section{B MCF-7}

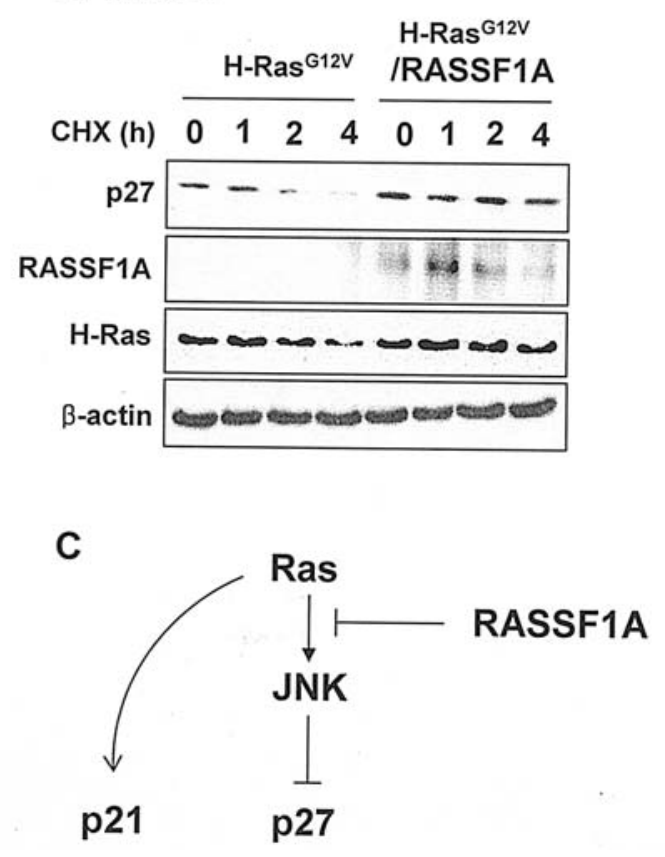

Figure 4. RASSF1A improved the levels of $\mathrm{p} 27^{\mathrm{Kip} 1}$ by increasing its halflife. $293 \mathrm{~T}$ (A) and MCF-7 (B) cells were transfected with $H$-Ras ${ }^{G 12 V}$ alone, or with $R A S S F 1 A$, and then treated with cycloheximide $24 \mathrm{~h}$ later. Extracts were subjected to SDS-PAGE and $\mathrm{p} 27^{\mathrm{Kip} 1}$ stability was assessed by Western blotting with anti-p27 Kip1 antibody. (C) Summary of the RASSF1A-inhibited oncogenic Ras signaling pathway.

induced $\mathrm{p} 27^{\mathrm{Kip} 1}$ down-regulation, we attempted to determine whether the recovery of $\mathrm{p} 27^{\mathrm{Kip} 1}$ expression by RASSF1A was post-transcriptional. We transfected $293 \mathrm{~T}$ and MCF-7 cells with $H$-Ras ${ }^{G 12 V}$ and RASSF $1 A$, treated with cycloheximide, and then examined $\mathrm{p} 27^{\mathrm{Kip} 1}$ expression via Western blotting. As shown in Fig. 4A and B, RASSF1A led to recovery of the levels of $\mathrm{p} 27^{\mathrm{Kip} 1}$ by increasing its half-life.

\section{Discussion}

Even though RASSF1A heterodimerizes with Nore 1 and is known to be a Ras effector, the precise mechanism by which RASSF1A suppresses activated Ras is not fully understood $(3,28)$. Ras plays an important role in the regulation of various cellular functions, including cell proliferation, differentiation, and malignant transformation (9). Constitutive activation of JNK is important for Ras-induced transformation, and $\mathrm{p} 27^{\mathrm{Kip} 1}$ down-regulation is a downstream event in Rastriggered cell cycle progression $(22,23)$. There are several reports demonstrating that one of many downstream mediators that is regulated by oncogenic Ras is JNK, and that it contributes to Ras-induced transformation (10-12). The constitutive activation of JNK by SAPKß-MKK7 induces transformation of NIH3T3 cells (19). A recent study has reported that RASSF1A expression inhibits JNK activity (21). In the present study, we showed that oncogenic H-Ras induced JNK activation and $\mathrm{p} 27^{\mathrm{Kip} 1}$ down-regulation, and that RASSF1A inhibited these events brought about by H-Ras ${ }^{\mathrm{G} 12 \mathrm{~V}}$.

As demonstrated above, the enhanced JNK activity related to $\mathrm{H}-\mathrm{Ras}^{\mathrm{G} 12 \mathrm{~V}}$ overexpression that resulted from exogenous transfection was not much affected by RASSF1A at a low level inside cells. Endogenous RASSF1A expression in 293T and BEAS-2B cells was not detectable by Western blotting in the present study (Fig. 1C and E). However, RASSF1A expression in these cells was detected by RT-PCR in a previous report (21) and again in this present study (Fig. 2A). We assumed that $\mathrm{H}-\mathrm{Ras}^{\mathrm{G} 12 \mathrm{~V}}$ overexpression could overcome the endogenous RASSF1A-mediated JNK suppression because RASSF1A was expressed at a low level in 293T and BEAS-2B cells. However, exogenous RASSF1A expression, which was detected by Western blotting (Fig. 1) and was enough to inhibit $\mathrm{H}-\mathrm{Ras}^{\mathrm{G} 12 \mathrm{~V}}$ activity, suppressed H-Ras-triggered JNK activation.

Since oncogenic Ras activates many signaling pathways involved in cellular transformation, it would be interesting to see whether RASSF1A also suppresses other Ras downstream events. Based on the results of this present study, we suggest that RASSF1A functions as a tumor suppressor by suppressing the oncogenic H-Ras-induced JNK pathway (Fig. 4C).

\section{Acknowledgements}

This study was supported by a grant (R01-2006-000-10113-0) from the Basic Research Program of the Korea Science \& Engineering Foundation, by a grant (R11-2005-017-01001-0) from the Research Center for Woman's Diseases of KOSEF, and by the National Nuclear R\&D Program of MOST/KOSEF (M20513000082-05B0900-08200).

\section{References}

1. Dammann R, Li C, Yoon JH, Chin PL, Bates S and Pfeifer GP: Epigenetic inactivation of a RAS association domain family protein from the lung tumour suppressor locus 3 p21.3. Nat Genet 25: 315-319, 2000.

2. Burbee DG, Forgacs E, Zochbauer-Muller S, Shivakumar L, Fong K, Gao B, Randle D, Kondo M, Virmani A, Bader S, Sekido Y, Latif F, Milchgrub S, Toyooka S, Gazdar AF, Lerman MI, Zabarovsky E, White M and Minna JD: Epigenetic inactivation of RASSF1A in lung and breast cancers and malignant phenotype suppression. J Natl Cancer Inst 93: 691-699, 2001.

3. Agathanggelou A, Cooper WN and Latif F: Role of the Rasassociation domain family 1 tumor suppressor gene in human cancers. Cancer Res 65: 3497-3508, 2005.

4. Liu L, Tommasi S, Lee DH, Dammann R and Pfeifer GP: Control of microtubule stability by the RASSF1A tumor suppressor. Oncogene 22: 8125-8136, 2003.

5. Song MS, Song SJ, Ayad NG, Chang JS, Lee JH, Hong HK, Lee H, Choi N, Kim J, Kim H, Kim JW, Choi EJ, Kirschner MW and Lim DS: The tumour suppressor RASSF1A regulates mitosis by inhibiting the APC-Cdc20 complex. Nat Cell Biol 6: 129-137, 2004. 
6. Shivakumar L, Minna J, Sakamaki T, Pestell R and White MA: The RASSF1A tumour suppressor blocks cell progression and inhibits cyclin D1 accumulation. Mol Cell Biol 22: 4309-4318, 2002.

7. Agathanggelou A, Bieche I, Ahmed-Choudhury J, Nicke B, Dammann R, Baksh S, Gao B, Minna JD, Downward J, Maher ER and Latif F: Identification of novel gene expression targets for the Ras association domain family 1 (RASSF1A) tumor suppressor gene in non-small cell lung cancer and neuroblastoma. Cancer Res 63: 5344-5351, 2003.

8. Ahmed-Choudhury J, Agathanggelou A, Fenton SL, Ricketts C, Clark GJ, Maher ER and Latif F: Transcriptional regulation of cyclin A2 by RASSF1A through the enhanced binding of p120E4F to the cyclin A2 promoter. Cancer Res 65: 2690-2697, 2005.

9. Downward J: Targeting RAS signalling pathways in cancer therapy. Nat Rev Cancer 3: 11-22, 2003.

10. Gupta S, Campbell D, Derijard B and Davis RJ: Transcription factor ATF2 regulation by the JNK signal transduction pathway. Science 267: 389-393, 1995.

11. Derijard B, Hibi M, Wu IH, Barrett T, Su B, Deng T, Karin M and Davis RJ: JNK1: a protein kinase stimulated by UV light and Ha-Ras that binds and phosphorylates the c-Jun activation domain. Cell 76: 1025-1037, 1994.

12. Xiao L and Lang W: A dominant role for the c-Jun NH2-terminal kinase in oncogenic ras-induced morphologic transformation of human lung carcinoma cells. Cancer Res 60: 400-408, 2000.

13. Raitano AB, Halpern JR, Hambuch TM and Sawyers CL: The Bcr-Abl leukemia oncogene activates Jun kinase and requires Jun for transformation. Proc Natl Acad Sci USA 92: 11746-11750, 1995.

14. Hess P, Pihan G, Sawyers CL, Flavell RA and Davis RJ: Survival signaling mediated by c-Jun $\mathrm{NH}(2)$-terminal kinase in transformed B lymphoblasts. Nat Genet 32: 201-205, 2002.

15. Antonyak MA, Moscatello DK and Wong AJ: Constitutive activation of c-Jun N-terminal kinase by a mutant epidermal growth factor receptor. J Biol Chem 273: 2817-2822, 1998.

16. Tsuiki H, Tnani M, Okamoto I, Kenyon LC, Emlet DR, Holgado-Madruga M, Lanham IS, Joynes CJ, Vo KT and Wong AJ: Constitutively active forms of c-Jun NH2-terminal kinase are expressed in primary glial tumors. Cancer Res 63: 250-255, 2003.

17. Hideshima T, Hayashi T, Chauhan D, Akiyama M, Richardson $P$ and Anderson K: Biologic sequelae of c-Jun $\mathrm{NH}(2)$-terminal kinase (JNK) activation in multiple myeloma cell lines. Oncogene 22: 8797-8801, 2003.
18. Potapova O, Gorospe M, Bost F, Dean NM, Gaarde WA, Mercola D and Holbrook NJ: c-Jun N-terminal kinase is essential for growth of human T98G glioblastoma cells. J Biol Chem 275: 24767-24775, 2000.

19. Rennefahrt UE, Illert B, Kerkhoff E, Troppmair J and Rapp UR: Constitutive JNK activation in NIH 3T3 fibroblasts induces a partially transformed phenotype. J Biol Chem 277: 29510-29518, 2002.

20. Smeal T, Binetruy B, Mercola DA, Birrer M and Karin M: Oncogenic and transcriptional cooperation with Ha-Ras requires phosphorylation of c-Jun on serines 63 and 73. Nature 354: 494-496, 1991.

21. Whang YM, Kim YH, Kim JS and Yoo YD: RASSF1A suppresses the c-Jun-NH2-kinase pathway and inhibits cell cycle progression. Cancer Res 65: 3682-3690, 2005.

22. Kerkhoff $E$ and Rapp UR: Cell cycle targets of Ras/Raf signalling. Oncogene 17: 1457-1462, 1998

23. Takuwa $\mathrm{N}$ and Takuwa $\mathrm{Y}$ : Ras activity late in $\mathrm{G} 1$ phase required for $\mathrm{p} 27^{\mathrm{kip} 1}$ downregulation, passage through the restriction point, and entry into S phase in growth factor-stimulated NIH 3T3 fibroblasts. Mol Cell Biol 17: 5348-5358, 1997.

24. Cheng M, Olivier P, Diehl JA, Fero M, Roussel MF, Roberts JM and Sherr CJ: The p21(Cip1) and p27(Kip1) CDK 'inhibitors' are essential activators of cyclin D-dependent kinases in murine fibroblasts. EMBO J 18: 1571-1583, 1999.

25. Yu J, Liu XW and Kim HR: Platelet-derived growth factor (PDGF) receptor-alpha-activated c-Jun NH2-terminal kinase-1 is critical for PDGF-induced $\mathrm{p} 21^{\mathrm{WAF} 1 / \mathrm{CIP} 1}$ promoter activity independent of p53. J Biol Chem 278: 49582-49588, 2003.

26. Coleman ML, Marshall CJ and Olson MF: RAS and RHO GTPases in G1-phase cell-cycle regulation. Nat Rev Mol Cell Biol 5: 355-366, 2004.

27. Yoo YA, Kim MJ, Park JK, Chung YM, Lee JH, Chi SG, Kim JS and Yoo YD: Mitochondrial ribosomal protein L41 suppresses cell growth in association with p53 and p27 $7^{\mathrm{Kip} 1}$. Mol Cell Biol 25: 6603-6616, 2005

28. Ortiz-Vega S, Khokhlatchev A, Nedwidek M, Zhang XF, Dammann R, Pfeifer GP and Avruch J: The putative tumor suppressor RASSF1A homodimerizes and heterodimerizes with the Ras-GTP binding protein Nore1. Oncogene 21: 1381-1390, 2002. 